\title{
Thermodynamic Analysis of Split Air Conditioner Using Energy and Exergy Viewpoint with Low GWP Refrigerants Alternative to R410A
}

\author{
Punit Mishra ${ }^{1, *}$, Shubham Soni ${ }^{2}$, and Govind Maheshwari ${ }^{3}$ \\ ${ }^{1,2} \mathrm{PhD}$ Scholar,Devi Ahilya University, Khandwa road, Indore (M.P), 452017, India \\ ${ }^{3}$ Department of Mechanical Engineering, Devi Ahilya University, Khandwa road, Indore (M.P), 452017, India
}

\begin{abstract}
In this paper, a comparative thermodynamic analysis on energy and exergy viewpoint is done on different low global warming potential (GWP) refrigerants to find the possible alternative of high GWP refrigerant R410A. R410A is used nowadays in air conditioning systems due to its ozone-friendly characteristic as zero ozone depletion potential (ODP $=0)$ but it has high GWP (GWP=1924) that leads to global warming. Now a day's global warming is considered to be one of the critical aspects when environmental protection is taken into consideration and researchers from every corner of the globe are working to find refrigerants that not only have zero ODP but it has low GWP too. In this analysis, four prospect refrigerants namely R32, R447A, R447B, and R452B have been studied to find their suitability to replace R410A on different performance criteria as the coefficient of performance (COP), power consumption, exergy efficiency, and exergy destruction. Thermodynamic properties of the studied refrigerants have been taken from the Genetron Properties 1.4 software. The result indicates that all the studied refrigerants have better performance characteristics compared to R410A but R447A has maximum $\mathrm{COP}$ and exergy efficiency along with the least total exergy destruction that makes it a possible alternate of R410A.
\end{abstract}

\section{Introduction}

Hydro-fluorocarbon (HFC) R410A is a mixture of R125 and R32 with $50 \%$ mass fraction of each refrigerant having $0.1^{\circ} \mathrm{C}$ of temperature glide [1]. This refrigerant performs well under a wide variety of medium and hightemperature applications area including air conditioners, dehumidifiers, and industrial applications. Recently it finds its successful application at $-30^{\circ} \mathrm{C}$ in an automotive heat pump system [2]. Although R410A have high energy performance along with ozone friendly characteristic but has very high global warming potential $(\mathrm{GWP}=1924)$ that leads to global warming and due to that researcher from every corner of the world are working to develop its alternative for the sake of environment protection. According to F-Gas Regulation No 517/2014 (EU 2014), and U.S. Environmental Protection Agency's (EPA) in 2016, introduced new regulations related to use of high GWP refrigerants in household HVAC systems [4]

To find an alternative to R410A with a single component was difficult on a performance basis as possible alternatives offer flammability issue that restricts their use whereas single component nonflammable refrigerants have a low volumetric capacity that leads to redesign of the existing system [5]. Fortunately, the blending of refrigerant is the possibility by which one can find the possible alternatives of R410A with the high-performance considerations. Several authors have presented R410A replacement with mixtures considering R32 as an important component in blends [6]-[8]. R32 (GWP = 677) is found to be an appropriate replacement for R410A, as it has very low GWP and requires less refrigerant mass compared to R410A operated system but due to its flammability issue can't be used in those applications which require a high refrigerant charge into the system. Currently, R32 is utilized extensively in domestic split-type airconditioners as in small residential units charging quantity of refrigerant is less and as per EU regulations. R32 operated system gives higher cooling capacity and high COP compared to R410A but the problem associated with it is the concern of flammability and high

* Corresponding author: enggpunit@gmail.com 
compressor discharge temperature. $\mathrm{Xu}$ et. al [9] in their experimental study showed that the compressor discharge temperature was found $20^{\circ} \mathrm{C}$ higher with R32 compared to R410A. In an experimental study, R32 showed better performance in resistance to leakage when compared with R410A [10] . Longo et.al [11] in their study finds that the frictional pressure drop for R32 was higher compared to R410A.

Now the emphasis is made to develop new refrigerant mixtures of Hydrocarbon (HC), HFC, hydrofluoro - olefin (HFO), and $\mathrm{CO}_{2}$ on the ground of low GWP with better safety considerations along with high energy and exergy performance. Sun et.al [12] in their experimental study uses the $\mathrm{R} 32 / \mathrm{CO}_{2}$ blend in heat pump system. In et.al [13] compared different refrigerants theoretically to find an alternative to R410A and found that R446A and R452B with $22 \%$ and $33 \%$ less GWP have lower energy consumption than R410A in refrigeration mode. With approximately identical operating pressures R452B shows similar cooling characteristics and COP compared to R410A[13]. Sethi et.al [14] make simulations with R452B and R447B refrigerants in residential reversible heat pump and the result showed similar cooling efficiency and cooling capacity under an ambient temperature of $35^{\circ} \mathrm{C}$ whereas for ambient temperature above $35^{\circ} \mathrm{C}, 3$ to $4 \%$ higher $\mathrm{COP}$ was calculated compared to R410A. To consider the effect of leak of R452B, when operated for a residential cooling system with CFD simulation, the volume fraction of the refrigerant was found to be less than $4 \%$, hence there is no risk associated with flammability [15]. The same type of leak analysis on a cooling unit (4 tons capacity) was performed with R452B and the conclusion was made that no potential cause was detected which would lead to potentially flammable events [16]. An investigation carried out to find drop in replacement of R410A using low GWP refrigerants as HPR2A, R447A, R454B, R459A, and R32 on $10 \mathrm{~kW}$ capacity reversible heat pump (air to water). The study shows that a mixture of HFC/HFO showed no specific problem to replace $\mathrm{R} 410 \mathrm{~A}$ with few exceptions, in the range of $+/-10 \%$. R454B and R459A also showed the best performances [17]. Mota-Babiloni et.al [18] have analyzed different new refrigerant mixtures performance alternatives to R410A. To understand the actual performance of the system and to know about the inefficiencies associated with an individual component, exergy analysis can be performed along with energy analysis gives better understanding of the system performance by finding the component in which the destruction of exergy is maximum and by minimizing it the energy as well as exergy efficient system can be designed. Saidur et.al [19] analyzed the utilization of energy and exergy in the domestic sector and find, energy efficiencies of $70 \%$ whereas exergy efficiencies was found $28 \%$ only. That shows a large scope for improvement on the performance of the system exergetically.

In this paper energy and exergy, parameters are calculated for four alternative refrigerants namely R32, R447A, R447B, and R452B to find their possibility to replace high GWP R410A. All the considered refrigerants have GWP lower than 750 that satisfy EU regulations for residential air conditioners. Table 1 gives Properties of R410A and alternatives refrigerants whereas table 2 shows the thermodynamic properties of the refrigerants taken in study.

TABLE 1. Properties of R410A and alternatives (Genetron Properties 1.4)

\begin{tabular}{|c|c|c|c|c|c|}
\hline Refrigerant & Composition & Mass \% & GWP & $\begin{array}{c}\text { ASHRAE } \\
\text { Class }\end{array}$ & $\begin{array}{c}\text { Tglide } \\
\left({ }^{\circ} \mathbf{C}\right)\end{array}$ \\
\hline R410A & R32+R125 & $50 \%+50 \%$ & 1924 & A 1 & 0.1 \\
\hline R32 & R32 & $100 \%$ & 677 & A2 & 0 \\
\hline R447A & R32+R125+R1234ze & $68 \%+3.5 \%+28.5 \%$ & 572 & A2L & 3.9 \\
\hline R447B & R32+R125+R1234ze & $68 \%+8 \%+24 \%$ & 714 & A2L & 3.3 \\
\hline R452B & R32+R1234yf & $68.9 \%+31.1 \%$ & 675 & A2L & 1 \\
\hline
\end{tabular}

TABLE 2. Thermodynamic properties of replacement refrigerants for R410A

\begin{tabular}{|c|c|c|c|c|c|}
\hline Properties & R410A & R32 & R447A & R447B & R452B \\
\hline Boiling point [K] & 221.7 & 221.3 & 227.4 & 223.2 & 222.5 \\
\hline Critical temperature $[\mathrm{K}]$ & 344.5 & 351.1 & 355.63 & 356.7 & 350.2 \\
\hline Critical pressure $[\mathrm{kPa}]$ & 4901 & 5782 & 5416.8 & 5644.7 & 5220.1 \\
\hline Liquid pressure $[\mathrm{kPa}]$ & 1664.1 & 1696.4 & 1524.1 & 1548.9 & 1592.2 \\
\hline Vapor pressure $[\mathrm{kPa}]$ & 1658.8 & 1689.6 & 1367.1 & 1412.2 & 1543.6 \\
\hline Liquid density $\left[\mathrm{kg} / \mathrm{m}^{3}\right]$ & 1057.8 & 960.38 & 1019.9 & 1020.23 & 992.82 \\
\hline Vapor density $\left[\mathrm{kg} / \mathrm{m}^{3}\right]$ & 66.27 & 47.55 & 44.27 & 46.17 & 52.63 \\
\hline Molar mass $\left(\mathrm{g} / \mathrm{mol}^{3}\right)$ & 72.59 & 52.024 & 63.05 & 63.12 & 63.52 \\
\hline $\begin{array}{c}\text { Liquid specific heat at } \\
\text { constant pressure }(\mathrm{kJ} / \mathrm{kgK})\end{array}$ & 1.7 & 1.93 & 1.75 & 1.76 & 1.79 \\
\hline Latent heat $(\mathrm{kJ} / \mathrm{kg})$ & 186.08 & 270.6 & 232.84 & 230.31 & 219.37 \\
\hline
\end{tabular}

Properties are evaluated at a temperature of $25.15^{\circ} \mathrm{C}$ 


\section{Energy and Exergy Analysis}

The layout diagram and pressure enthalpy diagram of VCR cycle with superheating and sub-cooling of refrigerant with liquid vapour heat exchanger are shown in Fig. 1 and Fig. 2 respectively.

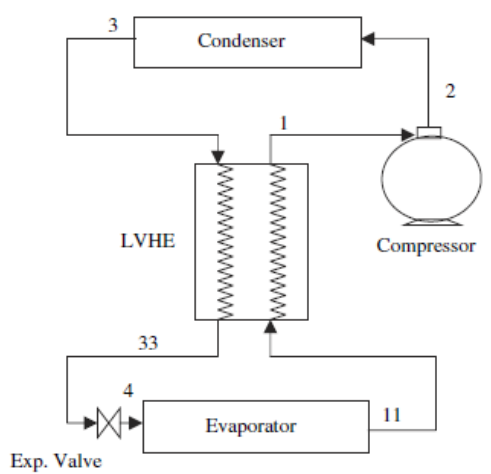

Fig.1 Layout diagram of VCR cycle with liquid vapour heat exchanger [20]

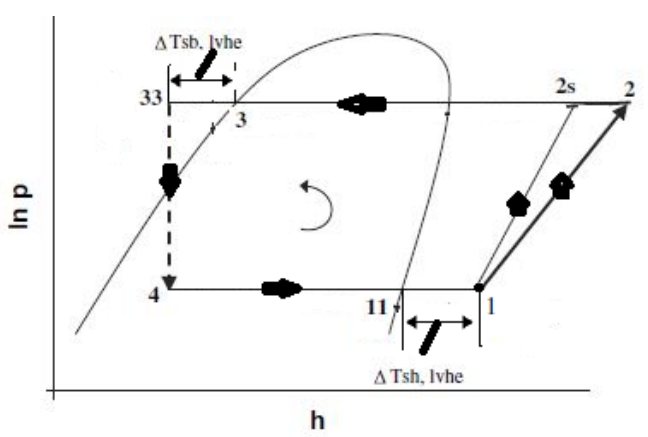

Fig.2 Pressure vs enthalpy diagram of VCR cycle with liquid vapour heat exchanger

Performance of any VCR system is evaluated primarily through COP, which is the ratio of desired refrigerating effect to the work supplied to the system and can be expressed as

$$
\operatorname{COP}=\frac{\dot{\mathrm{Q}}_{\mathrm{e}}}{\dot{\mathrm{W}}_{\text {comp }}}
$$

Where $\dot{\mathrm{Q}}_{\mathrm{e}}$ is the rate at which heat is absorbed in the evaporator in $\mathrm{kJ} / \mathrm{s}$,

$\dot{\mathrm{W}}_{\text {comp }}$ is the rate at which work is consumed in the compressor to drive the system in $\mathrm{kJ} / \mathrm{s}$

Theoretical Piston Displacement $\left(\dot{\mathrm{V}}_{\mathrm{P}}\right)$ can be calculated as:

$$
\dot{\mathrm{V}}_{\mathrm{P}}=\dot{\mathrm{m}}_{\mathrm{ref}} \times v_{\text {comp.in }}
$$

Where $v_{\text {comp,in }}$ is the specific volume $\left(\mathrm{m}^{3} / \mathrm{kg}\right)$ of the refrigerant entering to the compressor and $\dot{\mathrm{m}}_{\text {ref }}$ is the mass flow rate $(\mathrm{kg} / \mathrm{s})$ of the refrigerant in the system.

Volumetric Capacity $\left(\mathrm{kJ} / \mathrm{m}^{3}\right)$ can be calculated as:

$$
\text { Volumetric Capacity }=\frac{\mathrm{h}_{\text {evap,out }}-\mathrm{h}_{\text {evap,in }}}{v_{\text {comp,in }}}
$$

Where $h_{\text {eqag }}$ put and $h_{\text {frapin }}$ are the specific enthalpy $(\mathrm{kJ} / \mathrm{kg})$ at evaporator outlet and inlet respectively

Calculation from exergy viewpoint, when applied on different components of VCR system, is presented from equation 4 to equation 11 as [20]:

Evaporator

$$
\begin{gathered}
E \dot{D}_{\mathrm{e}}=\dot{\mathrm{E}}_{\mathrm{X}_{4}}+\dot{\mathrm{Q}}_{\mathrm{e}}\left(1-\frac{\mathrm{T}_{0}}{\mathrm{~T}_{\mathrm{r}}}\right)-\dot{\mathrm{E}}_{\mathrm{X}_{11}} \\
=\dot{m}_{\mathrm{r}}\left(\mathrm{h}_{4}-\mathrm{T}_{0} \mathrm{~s}_{4}\right)+\dot{\mathrm{Q}}_{\mathrm{e}}\left(1-\frac{\mathrm{T}_{0}}{\mathrm{~T}_{\mathrm{r}}}\right)-\dot{m}_{\mathrm{r}}\left(h_{11}-\mathrm{T}_{0} \mathrm{~S}_{11}\right)(4)
\end{gathered}
$$

Compressor

$$
E \dot{D}_{\text {comp }}=\dot{E}_{X_{1}}+\dot{W}_{\text {comp }}-\dot{E}_{X_{2}}=\dot{m}_{\mathrm{r}}\left(\mathrm{T}_{0}\left(\mathrm{~s}_{2}-\mathrm{s}_{1}\right)\right)(5)
$$

Condenser

$\mathrm{ED}_{\mathrm{c}}=\dot{\mathrm{E}}_{\mathrm{X}_{2}}-\dot{\mathrm{E}}_{\mathrm{X}_{3}}=\dot{m}_{\mathrm{r}}\left(\mathrm{h}_{2}-\mathrm{T}_{0} \mathrm{~s}_{2}\right)-\dot{m}_{\mathrm{r}}\left(\mathrm{h}_{3}-\mathrm{T}_{0} \mathrm{~s}_{3}\right)$

Throttle valve

$$
\begin{gathered}
\mathrm{ED}_{\mathrm{t}}=\dot{\mathrm{E}}_{\mathrm{x}_{33}}-\dot{\mathrm{E}}_{x_{4}} \\
=\dot{m}_{\mathrm{r}}\left(\mathrm{h}_{33}-\mathrm{T}_{0} \mathrm{~s}_{3}\right)-\dot{m}_{\mathrm{r}}\left(h_{4}-\mathrm{T}_{0} \mathrm{~s}_{4}\right) \\
=\dot{m}_{\mathrm{r}}\left(\mathrm{T}_{0}\left(\mathrm{~s}_{4}-\mathrm{s}_{33}\right)\right)
\end{gathered}
$$

Liquid vapour heat exchanger

$$
\mathrm{ED}_{\text {lvhe }}=\dot{\mathrm{E}}_{\mathrm{x}_{3}}-\dot{\mathrm{E}}_{\mathrm{x}_{33}}+\dot{\mathrm{E}}_{\mathrm{x}_{11}}-\dot{\mathrm{E}}_{\mathrm{x}_{1}}
$$

$=\dot{m}_{\mathrm{r}}\left(\left(h_{3}-h_{33}+h_{11}-h_{1}\right)-T_{0}\left(s_{3}-s_{33}+s_{1}-s_{11}\right)\right)$

Total exergy destruction (TED) is the sum total of the exergy destruction in different components and can be given as:

$$
\sum E \dot{D}_{\mathrm{i}}=E \dot{D}_{\mathrm{e}}+\mathrm{ED} \dot{D}_{\text {comp }}+\mathrm{ED}_{\mathrm{c}}+\mathrm{ED}_{\mathrm{t}}+\mathrm{ED_{ \text {lvhe } }} \text { (9) }
$$

Exergy efficiency is the ratio of actual COP to Carnot COP and can be given as:

\footnotetext{
* Corresponding author: enggpunit@gmail.com
} 


$$
\eta_{\mathrm{ex}}=\frac{\mathrm{COP}_{\mathrm{VCR}(\text { actual) }}}{\operatorname{COP}_{\mathrm{Carnot}}}
$$

Exergy destruction ratio (EDR) can be defined as the ratio of total exergy destruction ( $\mathbb{E D}_{\text {total }}$ ) to exergy in product ([IP)

$$
\mathrm{EDR}=\frac{\mathrm{ED_{ \text {total } }}}{\mathrm{EP}}=\frac{\mathrm{COP}_{\mathrm{rr}}}{\mathrm{COP}_{\mathrm{vcr}}}-1=\frac{1}{\eta_{\mathrm{ex}}}-1
$$

\section{Result and Discussion}

Here the analysis was made on a single-stage vapour compression refrigeration system of $1 \mathrm{TR}$ capacity with liquid suction heat exchanger, operating between the evaporation temperatures (Tevap) of $4.5^{\circ} \mathrm{C}$ whereas the condenser temperatures (Tcond) are taken from $40^{\circ} \mathrm{C}$ to $56^{\circ} \mathrm{C}$ in the interval of $4^{\circ} \mathrm{C}$.

Assumptions made for analysis are as follows:

- no pressure drop was considered in evaporator, liquid vapour heat exchanger, and condenser,

- heat transfer to or from the compressor, expansion device and connecting tubes were neglected,

- evaporator and condenser fan power consumption is not considered,

- no kinetic and potential energy changes were considered,

- Compressor isentropic efficiency $=0.75$ and compressor volumetric efficiency $=1$

- sub-cooling (condenser) $=3^{\circ} \mathrm{C}$ and superheating (evaporator) $=7^{\circ} \mathrm{C}$,

- superheat (suction line) $=4^{\circ} \mathrm{C}$ and the effectiveness (liquid vapour heat exchanger) $=0.7$

- dead state temperature $\left(\mathrm{T}_{0}\right)=25^{\circ} \mathrm{C}$

From fig. 3 shows the ratio of COP of corresponding refrigerant to COP of R410A operated system that shows all the studied refrigerants have COP higher than R410A at all condenser temperatures. At a lower condenser temperature of $40^{\circ} \mathrm{C}, 0.35-2.8 \%$ more COP was obtained but the same has been calculated $1.8-$ $5.3 \%$ higher when condenser temperature is at $56^{\circ} \mathrm{C}$. Maximum COP was calculated for R447A followed by R447B, R452B and R32. Although as the condenser temperature increases COP decreases and to counter this effect refrigerant selection plays a very important role.

Power consumption increases as the condenser temperature increases. Fig. 4 gives information about the power consumption of a VCR system when operated with a particular refrigerant to $\mathrm{R} 410 \mathrm{~A}$ operated system. It can be seen that all the considered refrigerants consume less power than R410A but the least power consumption is seen with R447A operated system. At lower condenser temperature variation in power consumption is less but as the condenser temperature increases significant savings in power consumption can be seen with the use of R447A and it consumes more than $5 \%$ less power than R410A operated system. The next proffered choice is R447B followed by R452B and R32. Fig. 5 gives information on the mass flow rate of the refrigerant required compared to $\mathrm{R} 410 \mathrm{~A}$ operated system. It can be seen that all the considered refrigerants require less mass flow rate as compared to R410 operated system. Significant saving was observed with R32 that needs about 35\% less mass compared to R410A operated system. R447A and R447B operated system needs $20 \%$ less mass compared to $\mathrm{R} 410 \mathrm{~A}$ whereas $\mathrm{R} 452 \mathrm{~B}$ requires $15 \%$ less mass flow rate than $\mathrm{R} 410 \mathrm{~A}$.

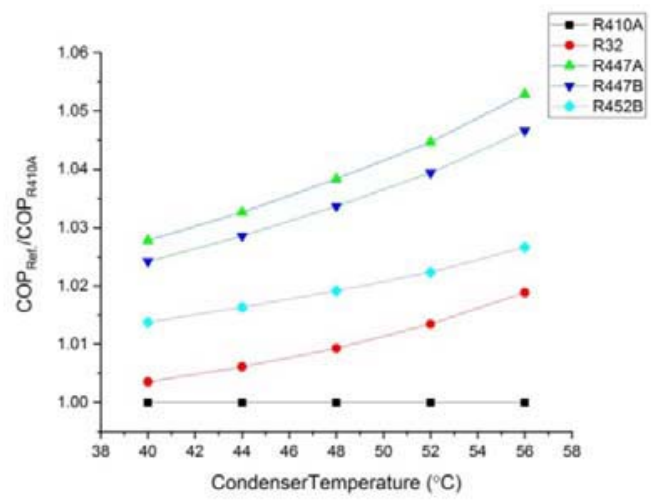

Fig. 3 Variation of COPRef/COPR410A with condenser temperature

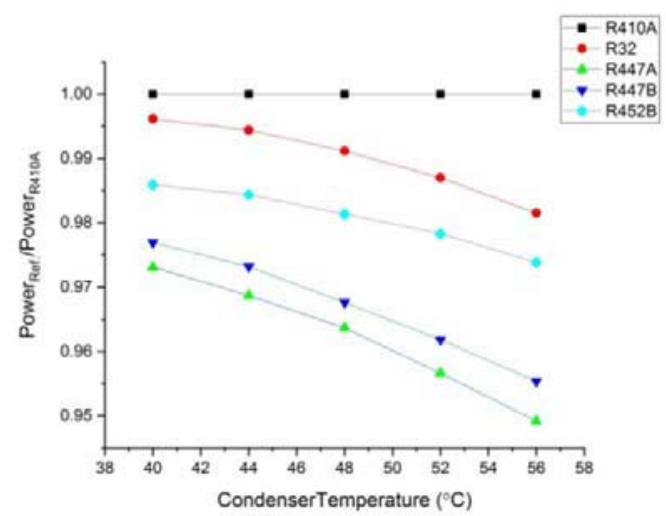

Fig. 4 Variation of PowerRef/Power R410A with condenser temperature

Variation in compressor displacement and volumetric cooling capacity with condenser temperature can be seen in fig.6. When the system is operated at a higher condenser temperature its 
compressor displacement increases and correspondingly volumetric cooling capacity decreases. Here R32 have the maximum volumetric cooling capacity among the studied refrigerants and it needs a small size compressor compared to all other refrigerants. $9.4 \%$ more volumetric cooling capacity was calculated with R32 compared to $\mathrm{R} 410 \mathrm{~A}$ when the condenser temperature of $56^{\circ} \mathrm{C}$ has been taken. R447A, R447B, and R452B compressor displacement is more than R410A operated system and accordingly, volumetric cooling capacity is less than R410A.

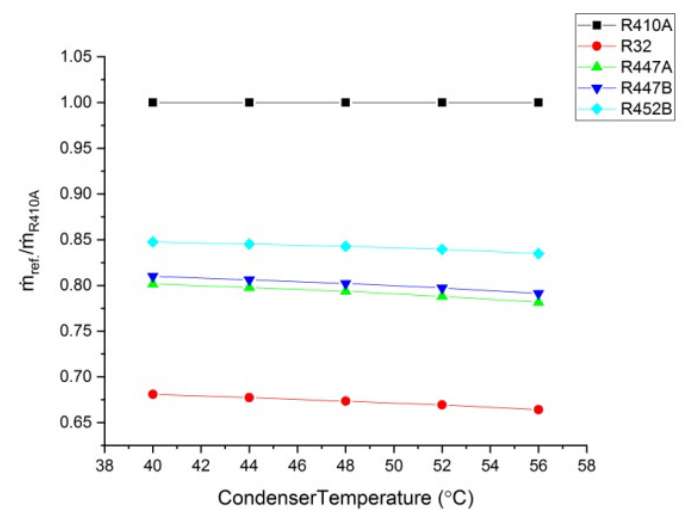

Fig.5 Variation of miRef/mR410A with condenser temperature

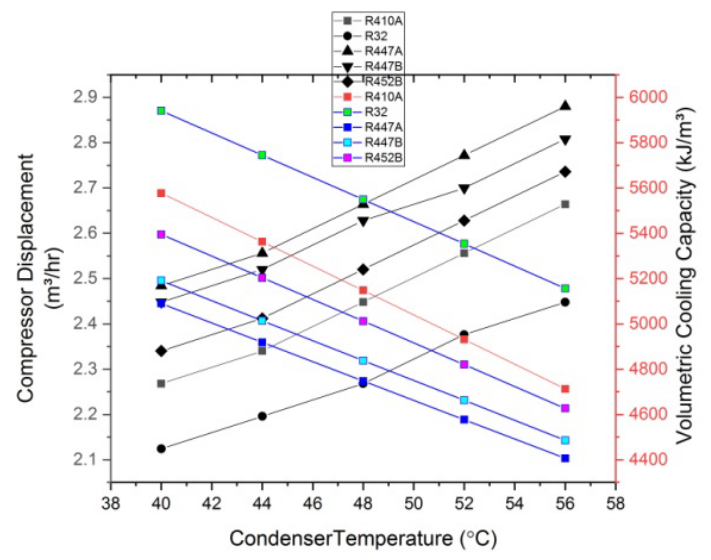

Fig.6 Variation of compressor displacement and volumetric cooling capacity with condenser temperature

The exergy efficiency of the VCR system decreases as the condenser temperature increases and this reduction in exergy efficiency is significant at higher condenser temperatures. It can be seen from fig. 7 that exergy efficiency at $40^{\circ} \mathrm{C}$ condenser temperature is around $33 \%-34 \%$ for all the studied refrigerants and it reduces drastically to just $20 \%-21 \%$ at a condenser temperature of $56^{\circ} \mathrm{C}$ and it shows that total exergy destruction (TED) is more at higher condenser temperature. TED is found maximum with R410A and least with R447A. Around $10 \%$ less TED was calculated with
R447A compared to $\mathrm{R} 410 \mathrm{~A}$ at a condenser temperature of $40^{\circ} \mathrm{C}$. At a condensing temperature of $56^{\circ} \mathrm{C} 13 \%$ less TED was calculated with R447A compared to R410A. Exergy destruction ratio (EDR) that provides the basis of total exergy destruction from the exergy of fuel (power supplied to the compressor) increases as the condenser temperature increases and this can be seen in fig. 8 . EDR increases drastically as it doubled when the condenser temperature changes from $36^{\circ} \mathrm{C}$ to $56^{\circ} \mathrm{C}$.

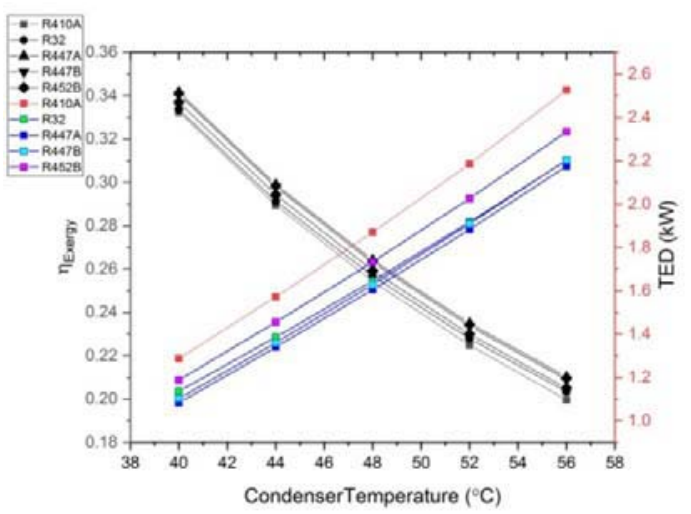

Fig.7 Variation of exergy efficiency and total exergy destruction with condenser temperature

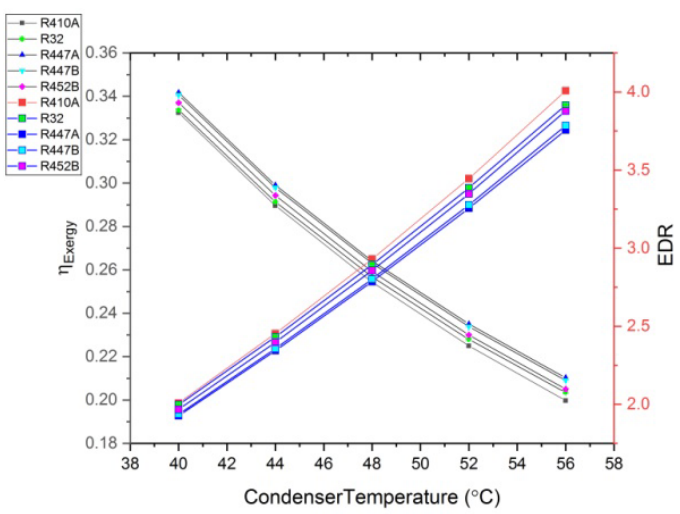

Fig.8 Variation of exergy efficiency and exergy destruction ratio with condenser temperature

\section{Conclusion}

Following conclusions can be made from the analysis and can be given as:

1. Although all the studied refrigerants have COP higher than R410A, COP of R447A operated system is found maximum and is $2.8 \%$ and $5.3 \%$ higher than $\mathrm{R} 410 \mathrm{~A}$ at condenser temperature of $40^{\circ} \mathrm{C}$ and $56^{\circ} \mathrm{C}$ respectively. In descending order of COP, the studied refrigerant can be given as R447A, R447B, R452B, R32, and R410A. On another 
side when power consumption is taken into consideration, here again, R447A is found to be energy efficient as it consumes the least power among all the studied refrigerants.

2. R32 is a flammable refrigerant but its charging quantity is $35 \%$ less than R410 for a given set of conditions and it reduces the risk of danger. Other studied refrigerants also need less mass flow rate compared to R410A.

3. R32 has maximum volumetric cooling capacity compared to all other refrigerants considered in the study and correspondingly its compressor capacity is least among all other studied refrigerants. The volumetric cooling capacity is found to be more with R447A, R447B and R452B when compared to $\mathrm{R} 410 \mathrm{~A}$ and due to that, a large compressor is required to attain the same cooling capacity that ultimately leads to redesigning of the existing system which increases the cost and weight of the system.

4. Total exergy destruction increases as the condenser temperature increases and it shows that inefficiencies are more at higher condensing temperatures.

5. Reduction in exergy efficiency is appreciable as it reduces from $33 \%$ to $20 \%$ for condenser temperature of $40^{\circ} \mathrm{C}$ to $56^{\circ} \mathrm{C}$.

6. Variation in exergy destruction ratio is drastic and it gets doubled when condenser temperature increases from $40^{\circ} \mathrm{C}$ to $56^{\circ} \mathrm{C}$.

Although no refrigerant is ideal and can meet all the desired objectives, a trade-off can be made to select the best possible alternative to $\mathrm{R} 410 \mathrm{~A}$ and here R447A is found more exergy efficient whereas from compactness, power, mass flow rate and cooling capacity viewpoint R32 is the suggested refrigerant that can replace R410A.

\section{References}

[1] B. Yu, H. Ouyang, J. Shi, W. Liu, J. Chen, Int. J. Refrig., vol. 121, 95 (2021).

[2] X. Zhai, K. Chen, SAE Tech. Pap. 2019-010910, (2019).

[3] E. 2014, Regul. No 517/2014 Eur. Parliam. Counc. 16 April 2014 fluorinated Greenh. gases repealing Regul. No 842/2006. Off. J. Eur. Union.

[4] SNAP, "Transitioning to Low-GWP Alternatives in Domestic Refrigeration," 2016.

[5] M. O. McLinden, J. S. Brown, R. Brignoli, A. F. Kazakov, P. A. Domanski, Nat. Commun., 8, 14476,( 2017).

[6] X. Xu, Y. Hwang, R. Radermacher, Int. J. Refrig., 36,. 892 (2013).

[7] X. Zhuang, R., Liang, Int. Congr. Refrig., 1 (2011).

[8] J. Chen, J. Yu, Energy Build., 40, 2022. (2008).

[9] S. Xu, X. Fan, G. Ma, Int. J. Refrig.. 75,. 286 (2017).

[10] G. He, W. Sun, Y. Zhu, X. Yang, D. Cai, Int. J. Refrig., 91, 177 (2018).

[11] G. A. Longo, S. Mancin, G. Righetti, C. Zilio, Int. J. Heat Mass Transf., vol. 125, 702 (2018).

[12] Z. Sun et al., "Experimental study on CO2/R32 blends in a water-to-water heat pump system," Aug. 2019.

[13] S. In, K. Cho, B. Lim, C. Lee, Appl. Therm. Eng., 85, 179, (2015).

[14] S. Sethi, A., Yana Motta, Int. Refrig. Air Cond. Conf., 1821., (2016).

[15]. O Bargach Abdelaziz,., S Shrestha,., B. Shen, , A.Elatar, , R.Linkous, , W Goetzler,. Y., "Alternative Refrigerant Evaluation for HighAmbient-Temperature Environments: R-22 and R-410A Alternatives for Rooftop Air Conditioners," no. ORNL/TM-2016/513., (2016).

[16] K. Kujak, S. Schultz, Int. Refrig. Air Cond. Conf., 1614, (2016)

[17] M. Pardo, Pierre and Mondot, Int. Refrig. Air Cond. Conf., Paper 1991, (2018).

[18] A. Mota-Babiloni, J. Navarro-Esbrí, Á. Barragán-Cervera, F. Molés, B. Peris, Int. J. Refrig., 52, 21 (2015).

[19] R. Saidur, H. H. Masjuki, M. Y. Jamaluddin, Energy Policy, 35, 1050 (2007).

[20] A. Arora, S. C. Kaushik, Int. J. Refrig., 31, 998, (2008). 